\title{
Poly(1,4-cyclohexanedimethylene 2,6-naphthalate) polyester with high melting point: Effect of different synthesis methods on molecular weight and properties
}

\author{
N. Kasmi ${ }^{1}$, Z. Terzopoulou ${ }^{1}$, G. Z. Papageorgiou², D. N. Bikiaris ${ }^{1 *}$ \\ ${ }^{1}$ Laboratory of Polymer Chemistry and Technology, Department of Chemistry, Aristotle University of Thessaloniki, \\ GR-541 24 Thessaloniki, Macedonia, Greece \\ ${ }^{2}$ Chemistry Department, University of Ioannina, P.O. Box 1186, 45110 Ioannina, Greece
}

Received 9 August 2017; accepted in revised form 19 October 2017

\begin{abstract}
In the current manuscript, a new approach for the synthesis of poly(1,4- cyclohexanedimethylene 2,6-naphthalate) (PCHDMN) derived from dimethyl 2,6-naphthalenedicarboxylate (2,6-DMN) and 1,4-Cyclohexanedimethanol (CHDM) via melt polycondensation method is introduced. The effect of three different synthesis pathways, polycondensation time and temperature on polyesters molecular weight increase has been investigated. All of the prepared samples were characterized measuring their intrinsic viscosity (IV), thermal properties and morphology with differential scanning calorimetry (DSC) and wide-angle X-ray diffraction (WAXD), respectively. The results demonstrated the effectiveness of the synthesis pathway proposed for the preparation of PCHDMN, resulting in high molecular weight (IV value around $0.5 \mathrm{dL} / \mathrm{g}$ ) and much shorter reaction time. Melt polycondensation temperatures above melting point of polyester should be avoided to be used due to the decomposition of polyester. This was proved by thermogravimetric analysis (TGA) and Pyrolysis-gas chromatography-mass spectroscopy analysis (Py-GC/MS).
\end{abstract}

Keywords: polymer synthesis, molecular engineering, 2,6-naphthalate polyesters, 1,4-cyclohexanedimethanol, thermal properties

\section{Introduction}

Naphthalate-based polyesters have grown most rapidly in recent years and they have found widespread use due to their extensive applications in engineering thermoplastics market $[1,2]$. Poly (m-methylene 2,6naphthalate)s $(\mathrm{PmN})$ are considered as the most important family of these polyesters with remarkable and unique properties. Two relevant polymers examples of this series, namely poly(ethylene 2,6 naphthalate) (PEN) and poly(butylene 2,6-naphthalte) (PBN), are intensively studied and commercialized for a wide range of applications. Because of the presence of the double naphthalene ring in their repeating units, they show excellent mechanical properties, high chemical resistance, high heat deflection temperature as well as dimensional stability, which meet the demanding requirements for flexible electronics, electronic packaging devices, connectors and biosensor applications [3]. More examples of PmN family include poly(hexamethylene 2,6-naphthalate) (PHN) [4], poly(trimethylene 2,6-naphthalate) (PTN), which has potential applications for special barrier films $[5,6]$ and poly(pentamethylene 2,6-naphthalate) (PPN) [7].

To give better thermal and mechanical properties to these PmN polyesters, the incorporation of 1,4-cyclohexanedimethanol (CHDM) has been investigated in view of its attractive features such as its rigidity

*Corresponding author, e-mail: $\underline{\text { dbic@,chem.auth.gr }}$ (C) BME-PT 
and high thermal stability [8]. Poly(1,4-cyclohexanedimethylene 2,6-naphthalate) (PCHDMN) was prepared and studied by Jeong et al. [9]. However, this study is more focused on crystal structure determination of PCHDMN, while some limited studies have been published on the synthesis of related copolyesters [10-13]. These copolyesters exhibited better properties, such as high heat resistance and low oxygen permeability, compared with their terephthalate analogues.

As can be seen, limited studies have been published concerning synthesis and characterization of the homopolyester PCHDMN, despite its high relevance thanks to its interesting properties. Thus, in the present study emphasis has been given to develop a new synthetic method for high molecular weight PCHDMN production via melt polycondensation process following different routes. The effect of reaction time and temperature on molecular weight of this polyester has been investigated.

\section{Experimental}

\subsection{Materials}

1,4-cyclohexanedimethanol (CHDM, 70/30 trans/cis, purum 99\%) (CAS Number: 105-08-8) and titanium (IV) isopropoxide (TIS) (purum 97\%) (CAS Number: 546-68-9) catalyst were purchased from SigmaAldrich Chemical Co (Chemie GmbH, Germany), dimethyl 2,6-naphthalenedicarboxylate (2,6-DMN, 98\%) was provided by Amoco Chemical Belgium.

\subsection{Polyester synthesis}

A detailed description of PCHDMN synthesis, using three different routes, via melt polycondensation has been presented below:

The synthesis of PCHDMN was carried out according to the method described in literature [9], wherein 2,6-DMN and CHDM at a molar ratio of 2,6-DMN/ $\mathrm{CHDM}=1 / 2$ were charged in a glass batch reactor with $400 \mathrm{ppm}$ TIS. In the first stage of transesterification, the reaction mixture was heated at $250{ }^{\circ} \mathrm{C}$ for $3 \mathrm{~h}$ under nitrogen atmosphere. In the second step of polycondensation of the formed bis-hydroxy-1,4-cyclohexanedimethanol naphthalate $(\mathrm{BHCN})$ oligomers, a high-vacuum (5.0 Pa) was applied slowly and the temperature was increased to $340^{\circ} \mathrm{C}$. During polycondensation, samples were taken every $15 \mathrm{~min}$ and are abbreviated as: PCHMDN.1.0 (0 min), PCHDMN.1.1 (15 min), PCHDMN.1.2 (30 min), PCHDMN.1.3 (45 $\mathrm{min}$ ) and PCHDMN.1.4 (60 $\mathrm{min})$.
In a second synthetic attempt the first step for oligomer formation was the same as reported before, but the formed BHCN oligomers were cooled down and an equimolar amount of 2,6-DMN was added (BHCN/2,6-DMN 1/molar ratio) following the procedure described in our previous paper [14]. The added amount of 2,6-DMN at this step was calculated considering that all initial 2,6-DMN/CHDM amounts have been completely reacted and oligomers have been formed. The reaction temperature was increased gradually to $250^{\circ} \mathrm{C}$ and was kept constant for $0.5 \mathrm{~h}$. Afterwards, the second stage of polycondensation was conducted at high-vacuum $(5.0 \mathrm{~Pa})$ and the temperature was increased to $300^{\circ} \mathrm{C}$ and kept there for $1.5 \mathrm{~h}$. Samples were taken every $0.5 \mathrm{~h}$ and are abbreviated as: PCHDMN.2.1 (0.5 h), PCHDMN.2.2 (1 h) and PCHDMN.2.2 (1.5 h).

Another synthesis route of PCHDMN was tested, via the usual two-stage polycondensation, using a stoichiometric molar ratio of 2,6-DMN/CHDM = 1/1 in presence of $400 \mathrm{ppm}$ of TIS. The reaction mixture was heated, during the transesterification stage under a nitrogen atmosphere, at $270{ }^{\circ} \mathrm{C}$ for $0.5 \mathrm{~h}$. In the second step of polycondensation, the pressure was reduced (5.0 Pa) and the reaction temperature was kept at $290{ }^{\circ} \mathrm{C}$ for $1.5 \mathrm{~h}$. Samples were taken every $0.5 \mathrm{~h}$ and are abbreviated as: PCHMDN.3.1 (0.5 h), PCHDMN.3.2 ( $1 \mathrm{~h})$ and PCHDMN.3.3 (1.5 h).

\subsection{Polyester characterization}

Intrinsic viscosity [IV] measurements of the prepared polyesters were performed with an Ubbelohde viscometer at $25^{\circ} \mathrm{C}$ in a mixture of phenol/tetrachloroethane $(60 / 40 \mathrm{w} / \mathrm{w})$. Wide angle X-ray diffraction patterns (WAXD) of the samples were recorded using a MiniFlex II XRD system from Rigaku Co (Tokyo, Japan), with $\mathrm{CuK}_{\alpha}$ radiation $(\lambda=0.154 \mathrm{~nm})$ in the angle $2 \theta$ range from 5 to 60 degrees. For thermal analysis measurements, a Perkin-Elmer (Waltham MA, USA), Pyris Diamond differential scanning calorimeter (DSC), coupled with an Intracooler 2P cooling accessory, was used. Samples of $6 \pm 0.1 \mathrm{mg}$ were sealed in aluminum pans. Each sample was heated from 30 to $350^{\circ} \mathrm{C}$ at a heating rate of $20^{\circ} \mathrm{C} / \mathrm{min}$ under nitrogen flow $(20 \mathrm{~mL} / \mathrm{min})$, and held at this temperature for $2 \mathrm{~min}$ to erase any thermal history. After that, the sample was cooled down to $30^{\circ} \mathrm{C}$ at a cooling rate of $20^{\circ} \mathrm{C} / \mathrm{min}$. Fourier transformed-infrared spectroscopy (FTIR) spectra were obtained using a Perkin-Elmer FTIR spectrometer (Waltham 
MA, USA), model Spectrum One, in the spectral region of $400-4000 \mathrm{~cm}^{-1}$ using a resolution of $4 \mathrm{~cm}^{-1}$ and 64 co-added scans.

${ }^{1} \mathrm{H}-\mathrm{NMR}$ spectrum of polyester was obtained with a Bruker spectrometer (Bremen, Germany) operating at a frequency of $500 \mathrm{MHz}$ for protons using deuterated trifluoroacetic acid (d-TFA) as solvent in order to prepare solutions of $5 \% \mathrm{w} / \mathrm{v}$. The number of scans was 16.

For Pyrolysis-gas chromatography-mass spectroscopy analysis (Py-GC/MS), a very small amount of each material is 'dropped' initially into the 'Double-Shot' EGA/PY 3030D Pyrolyzer (Frontier Laboratories Ltd, Fukushima Japan) using a CGS-1050Ex (Japan) carrier gas selector. The pre-selected pyrolysis temperature was $350^{\circ} \mathrm{C}$ and the $\mathrm{GC}$ oven temperature was heated from 50 to $300^{\circ} \mathrm{C}$ at $10^{\circ} \mathrm{C} / \mathrm{min}$. Sample vapors generated in the furnace were split (at a ratio of $1 / 50$ ), a portion moved to the column at a flow rate of $1 \mathrm{~mL} / \mathrm{min}$, pressure $53.6 \mathrm{kPa}$ and the remaining portion exited the system via the vent. The pyrolyzates were separated using temperature programmed capillary column of a Shimadzu QP-2010 Ultra Plus (Japan) gas chromatogram and analysed by the mass spectrometer MS QP2010SE of Shimadzu (Japan) use $70 \mathrm{eV}$. Ultra-ALLOY ${ }^{\circledR}$ metal capillary column from Frontier Laboratories LTD (Fukushima Japan) was used containing 5\% diphenyl and 95\% dimethylpolysiloxane stationary phase, column length $30 \mathrm{~m}$ and column ID $0.25 \mathrm{~mm}$. For the mass spectrometer, the following conditions were used: Ion source heater $200^{\circ} \mathrm{C}$, interface temperature $300^{\circ} \mathrm{C}$, vacuum $10-4-100 \mathrm{~Pa}, \mathrm{~m} / \mathrm{z}$ range $45-500 \mathrm{amu}$ and scan speed 10000 . The chromatogram and spectra retrieved by each experiment were subject to further interpretation through Shimadzu and Frontier post-run software.

\section{Results and discussion}

Optimization of experiments has been performed to find the best reaction conditions for the synthesis of the polyester PCHDMN regarding its molecular weight. The important parameters to be investigated were the reaction time and temperature. The strategy used here consists of carrying out three synthesis reactions at different conditions as indicated in Figure 1 (described in the experimental section).

By applying the mentioned method from literature [9] very low IV value was achieved from the beginning of polycondensation and as can be seen from

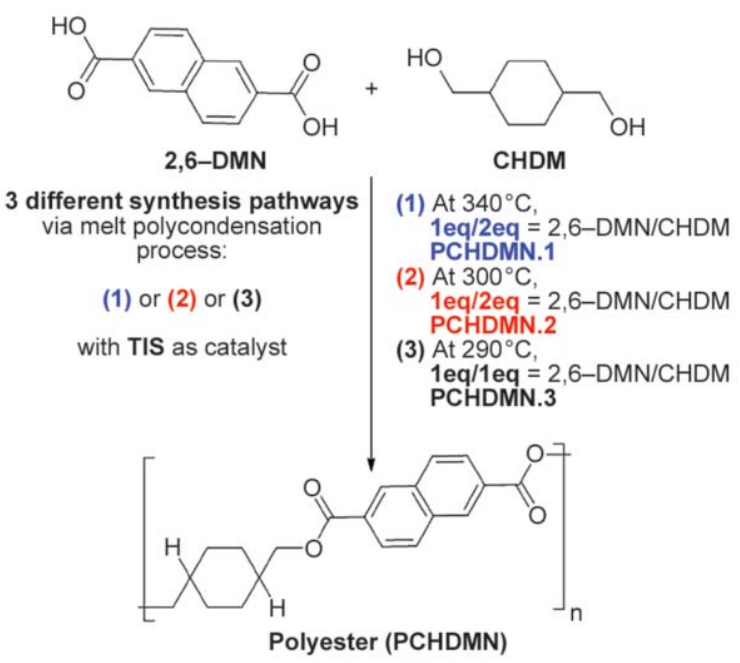

Figure 1. Synthetic route of Polyester (PCHDMN) via three different pathways

Figure 2 (samples PCHDMN.1) this was decreased continuously from 0.25 to $0.10 \mathrm{dL} / \mathrm{g}$ with increasing the polycondensation time. This was due to the negative effect of the high reaction temperature of the second polycondensation stage $\left(340^{\circ} \mathrm{C}\right)$, which finally seems to result in the decomposition of the polyester PCHDMN. These values are much lower compared to those in the study of Jeong et al. [9] wherein an IV value of $0.48 \mathrm{dL} / \mathrm{g}$ was obtained, using a reaction temperature of $330-350^{\circ} \mathrm{C}$. Furthermore, CHMD has very high boiling point (about $283^{\circ} \mathrm{C}$ ) and thus it is very difficult to be removed from the polyester melt. However, removal of the diol is needed in the stage of polycondensation, in order the polyester molecular weight to increase. For this reason, based on our previous experience [14],

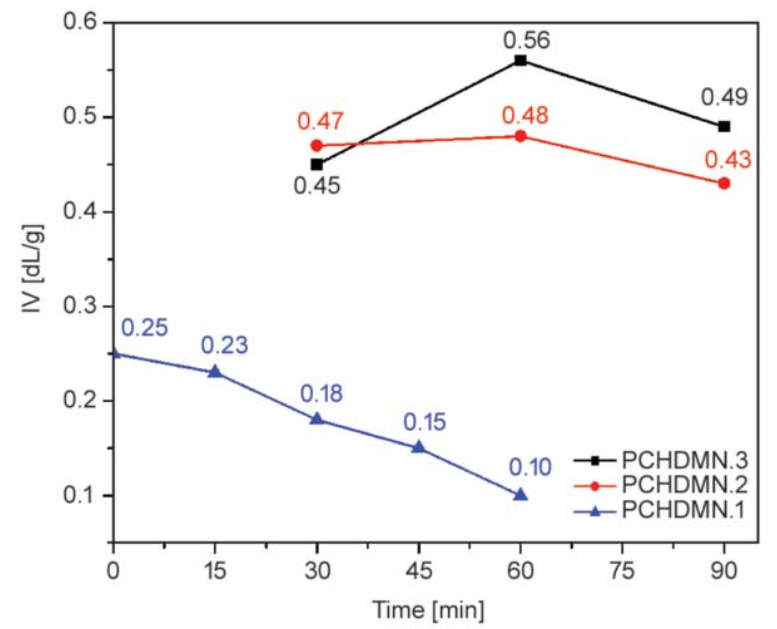

Figure 2. Variation of the intrinsic viscosity with time of PCHDMN.1, PCHDMN.2 and PCHDMN.3 polyesters 


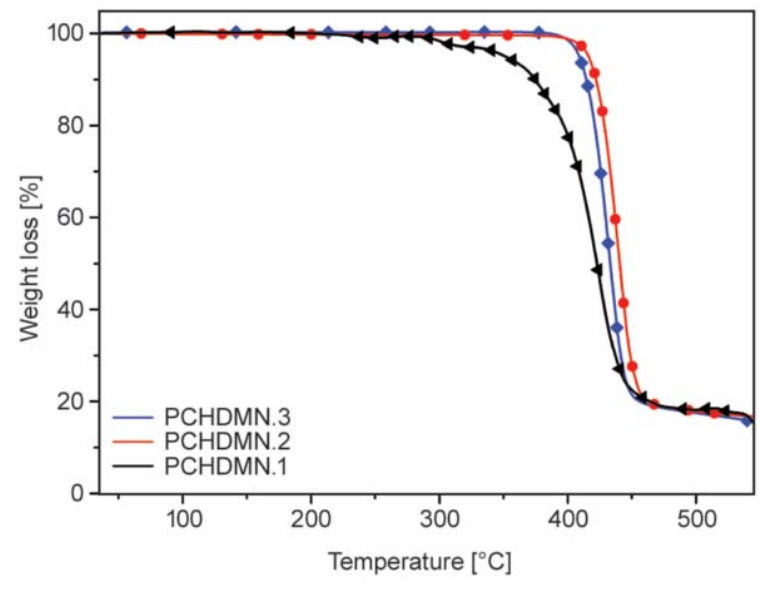

Figure 3. TGA thermograms of the PCHDMN polyesters

we differentiated this method and after the first stage of transesterification and $\mathrm{BHCN}$ oligomers formation, 2,6-DMN was added in equimolar amount. At $250^{\circ} \mathrm{C}$ a liquid was initially formed, since both oligomers and added 2,6-DMN are melted, but almost after 15 min a solid material was formed. This is an indication that reaction occurred rapidly, and high molecular weight polyester was formed. To avoid polyester decomposition, in the subsequent stage of polycondensation the temperature was kept at $300^{\circ} \mathrm{C}$, which is much lower temperature than in the initial procedure $\left(340^{\circ} \mathrm{C}\right)$. At $300^{\circ} \mathrm{C}$, the polyester is solid, though very close to the melting temperature, and polycondensation takes place in solid state. From the collected samples, it can be seen that after $30 \mathrm{~min}$ polycondensation the polyester has a high value IV $=$ $0.47 \mathrm{dL} / \mathrm{g}$ and increased further to $0.48 \mathrm{dL} / \mathrm{g}$ after $60 \mathrm{~min}$. However, after $90 \mathrm{~min}$ at $300^{\circ} \mathrm{C}$ a slight reduction was recorded to $\mathrm{IV}=0.43 \mathrm{dL} / \mathrm{g}$, indicating that even at such low polycondensation temperatures, decomposition can take place, though in much lower extent compared to $340^{\circ} \mathrm{C}$.

Besides these 2 procedures, a third strategy was tested involving use of equal amounts of 2,6-DMN and CHDM. It is amazing that even after only after $15-$ $20 \mathrm{~min}$ of reaction at $270^{\circ} \mathrm{C}$, the liquid melt became solid, which means that rapidly high molecular polyester was prepared. The temperature was increased to $290^{\circ} \mathrm{C}$ and solid state polycondensation proceeded for different durations. After $30 \mathrm{~min}$ the polyester showed an IV $=0.45 \mathrm{dL} / \mathrm{g}$, which increased to IV = $0.56 \mathrm{dL} / \mathrm{g}$ after $60 \mathrm{~min}$, before finally decrease slightly to IV $=0.49 \mathrm{dL} / \mathrm{g}$ after $90 \mathrm{~min}$ polycondensation. According to this, for a reaction temperature at $290{ }^{\circ} \mathrm{C}$, even a short reaction time $(0.5 \mathrm{~h})$ is quite enough to synthesize PCHDMN with high IV value.
Also, from all the tested methods, it was proved that a moderate reaction temperature is necessary to improve the molecular weight of the polyester. As was found from thermogravimetric analysis (TGA) (Figure 3), even though for PCHDMN the temperature for maximum decomposition rate is as high as $440^{\circ} \mathrm{C}$, its decomposition starts at much lower temperatures. So, in the temperature range $330-380^{\circ} \mathrm{C}$ the polyesters lost almost $0.3 \%$. This seems a very small mass loss but when the polycondensation is taking place isothermally at $340^{\circ} \mathrm{C}$ for prolonged times, decomposition proceeds progressively deteriorating the properties of the formed PCHDMN, finally reducing the molecular weight.

The FTIR spectra confirmed the high extent of decomposition that takes place at such elevated temperatures (Figure 4). The FT-IR spectra of all the prepared polyesters by applying these 3 methods (PCHDMN.1, PCHDMN.2 and PCHDMN.3) are consistent with the corresponding molecular structure of polyester. The main characteristic peaks were: at $3065 \mathrm{~cm}^{-1}$ assigned to naphthalate $=\mathrm{CH}$ groups, 2930 and $2861 \mathrm{~cm}^{-1}$ due to $-\mathrm{CH}_{2}$ of CHDM unit, $1716 \mathrm{~cm}^{-1}$ attributed to ester moiety $>\mathrm{C}=\mathrm{O}$ group and another band at $1259 \mathrm{~cm}^{-1}$ assigned to $-\mathrm{C}-\mathrm{O}-\mathrm{C}-$. However, in PCHDMN.1 samples there are some minor differences. The ester peak is shifted to $1709 \mathrm{~cm}^{-1}$, maybe due to the high number of $-\mathrm{COOH}$ end groups and a high intensity peak appeared at $1630 \mathrm{~cm}^{-1}$, due to formed vinyl groups. These changes can be explained considering the main degradation mechanism of PCHDMN involving via $\beta$-hydrogen bond scission, leading to the formation of vinyl end groups and $-\mathrm{COOH}$. Also, the peak corresponding to $-\mathrm{OH}$

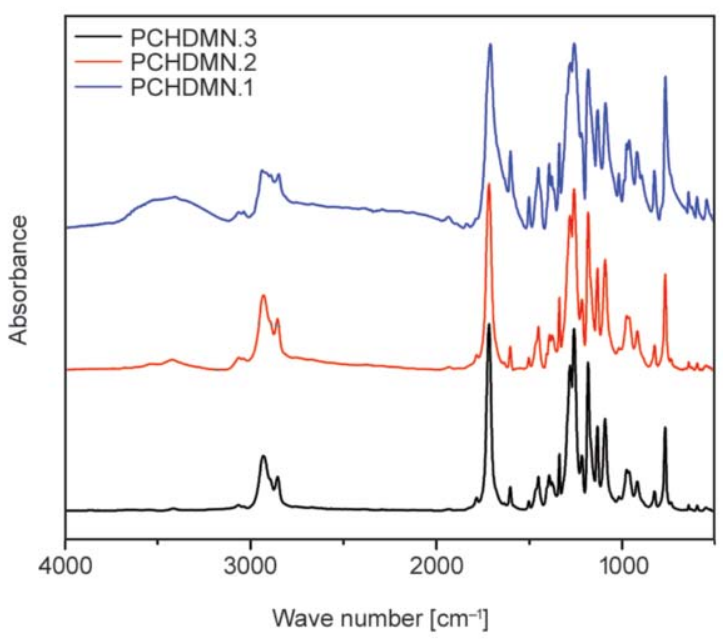

Figure 4. FT-IR spectra of the polyesters: PCHDMN.1 (1 h), PCHDMN.2 and PCHDMN.3 
groups between $3200-3700 \mathrm{~cm}^{-1}$ has much higher intensity, compared to these of the other two samples (PCHDMN.2 and PCHDMN.3). All these differences are due to the extensive decomposition of PCHDMN.1 polyester, which is in good agreement with its low IV values.

The chemical structure of the prepared polyesters (PCHDMN.2 and PCHDMN.3) was confirmed by ${ }^{1} \mathrm{H}-\mathrm{NMR}$ spectroscopy, as shown in Figure 5 . The resonances appeared at (b) 8.83 and (a) 8.28 ppm correspond to the naphthalene ring protons. Two peaks at 4.66 and $4.52 \mathrm{ppm}$ were respectively assigned to the cis- and trans-methylene protons in CHDM, designated as (c). The resonances ranging from 1.46 to $2.37 \mathrm{ppm}$ were attributed to the methylene and methine protons of the cyclohexane ring labelled (d) and (e), wherein their chemical shifts are dependent on the equatorial (eq) or axial (ax) substitution of the cis/trans isomers. The detailed indexation of (e) and (d) protons is depicted in Figure 5, which is in accordance with the one found in Hong et al. [15].
The DSC thermograms of the as-received samples PCHDMN.1, PCHDMN.2, PCHDMN.3 are reported in Figure 6. The DSC traces of all as received PCHDMN.2 and PCHDMN.3 samples are typical of semi crystalline materials, since only a clear melting peak is recorded. PCHDMN.3 samples exhibit a progressive increase of their melting points from 342.5 to $345.7^{\circ} \mathrm{C}$, and $346.7^{\circ} \mathrm{C}$ with increasing the reaction time from 0.5 to $1 \mathrm{~h}$ and $1.5 \mathrm{~h}$, respectively. The high melting temperature $\left(T_{\mathrm{m}}\right)$ is related to the high crystallinity of the polyester (PCHDMN) [16]. The samples PCHDMN.2 also show an increasing trend of $T_{\mathrm{m}}$ (Figure 6b), starting from 321.9, 325.5, and $332.6^{\circ} \mathrm{C}$ with increasing the reaction time from 0.5 , to $1 \mathrm{~h}$ and $1.5 \mathrm{~h}$, respectively and this behavior should be attributed to the lower crystallinity of these polyesters. These melting points are similar to that reported from Jeong et al. [9]. Figure $6 \mathrm{c}$ shows the DSC curves of the PCHDMN.1 samples, prepared at the high reaction temperature of $340^{\circ} \mathrm{C}$. Serious alterations in all characteristic thermal parameters

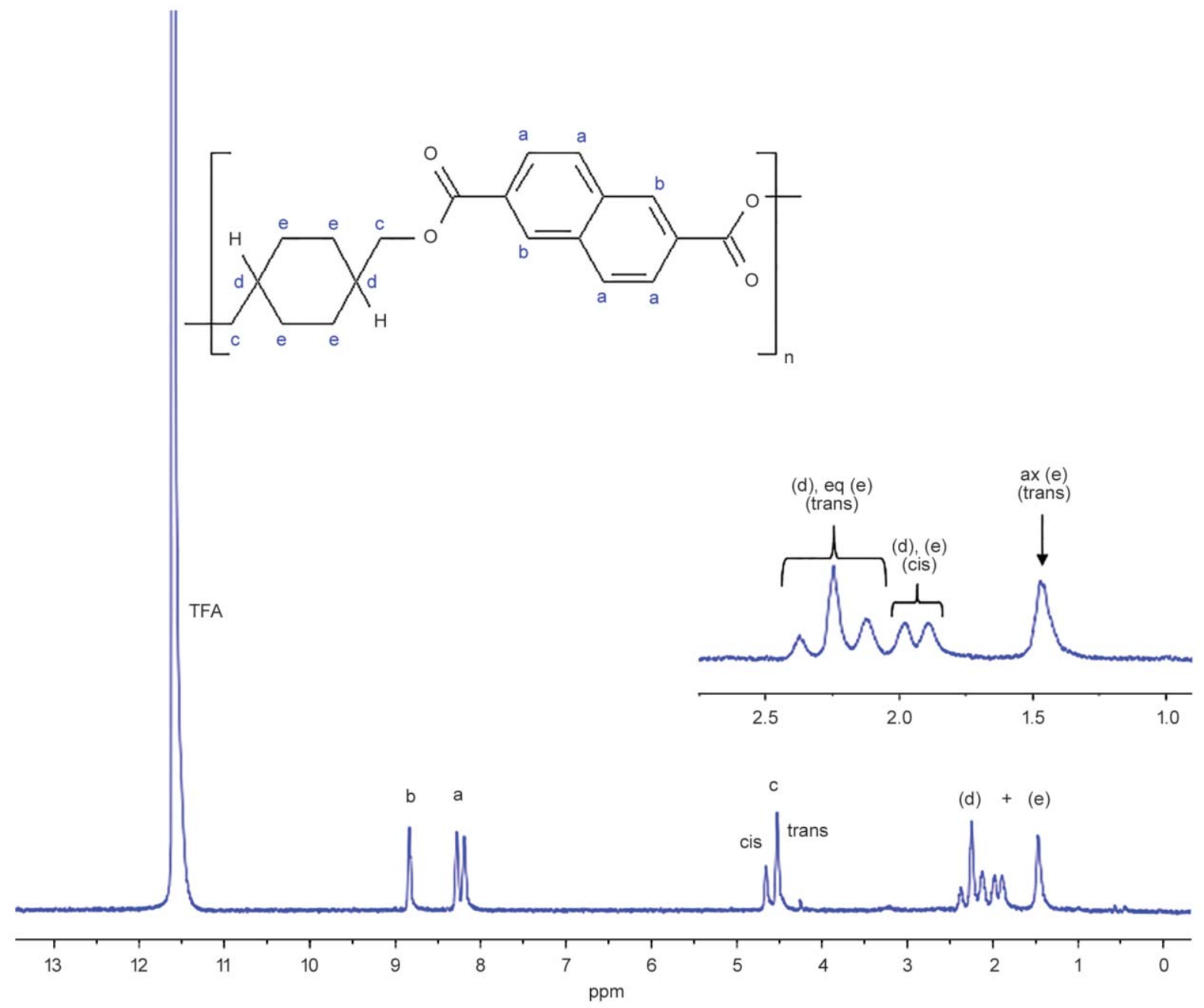

Figure 5. ${ }^{1} \mathrm{H}-\mathrm{NMR}$ spectrum of the PCHDMN polyester 

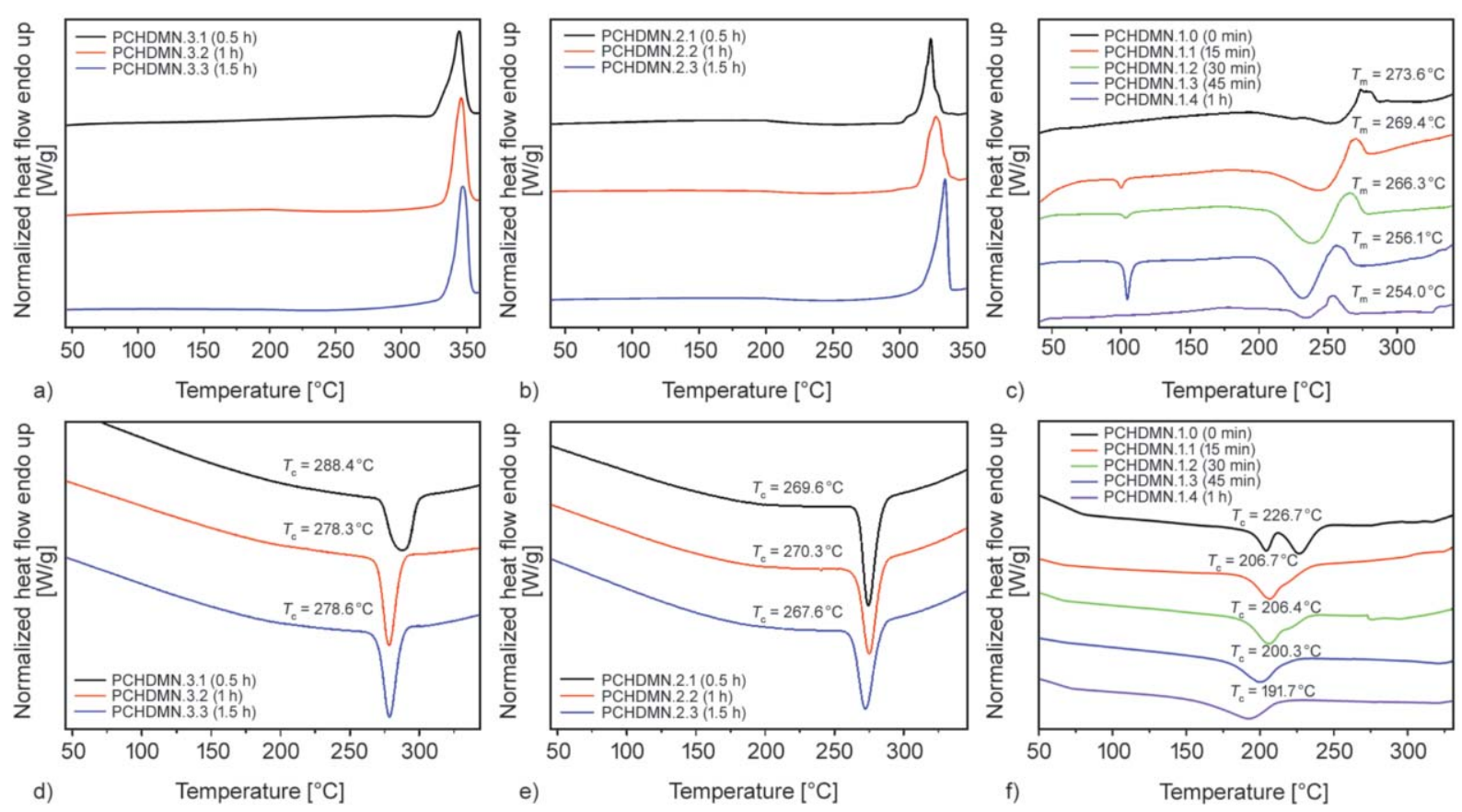

Figure 6. DSC thermograms of the as-prepared polyesters samples during heating: a) PCHDMN.3, b) PCHDMN.2, c) PCHDMN.1 and during cooling from their melt: d) PCHDMN.3, e) PCHDMN.2 and f) PCHDMN.1

have been observed, comparing with PCHDMN.2 and PCHDMN.3 samples. As can be seen, PCHDMN.1 samples are semi crystalline materials with very low degree of crystallinity since just before their melting points there is an exothermic crystallization peak. Furthermore, their melting points are found to be affected distinctly by the increase of the reaction time of polycondensation stage, decreasing steadily from 273.6 to $254^{\circ} \mathrm{C}$ with increasing time. The melting temperatures are much lower compared to corresponding for polyesters prepared with the other 2 methods. This dramatic shift of $T_{\mathrm{m}}$ to lower values with increasing the reaction time can be associated with the low molecular weights of the samples, which is in good agreement with the observed IV values.

Crystallization thermograms recorded on cooling at $10^{\circ} \mathrm{C} / \mathrm{min}$ for all the samples are presented in Figure $6 \mathrm{~d}-6 \mathrm{f}$. The crystallization temperature $\left(T_{\mathrm{c}}\right)$ values of PCHDMN.2 decreased from 269.6, to $270.3^{\circ} \mathrm{C}$, and finally $267.6^{\circ} \mathrm{C}$, respectively with increasing the reaction time from 0.5 , to $1 \mathrm{~h}$ and $1.5 \mathrm{~h}$, while $T_{\mathrm{c}}{ }^{\mathrm{s}}$ of PCHDMN.3 samples were 288.4, 278.3, and $278.6^{\circ} \mathrm{C}$, respectively. The crystallization temperatures of PCHDMN.1 samples are much lower, in the range between 226.7 and $191.7^{\circ} \mathrm{C}$. So, it seems that the extended decomposition that takes place, also affects crystallization temperatures of PCHDMN.1 samples.
The high crystalline samples PCHDMN.2 and PCHDMN.3 were also quenched from their melt prior to be obtained as completely amorphous. In the DSC curves of these samples (Figure 7) a glass transition temperature was recorded at 113.2 and $112.4^{\circ} \mathrm{C}$, respectively, followed by cold crystallization at 160.4 and $158.0^{\circ} \mathrm{C}$. The corresponding melting temperatures were 315.6 and $316.9^{\circ} \mathrm{C}$. The obtained DSC traces are in good agreement with those reported in literature [9] but the melting temperatures are lower compared with initial semicrystalline samples (Figures 6a, 6b).

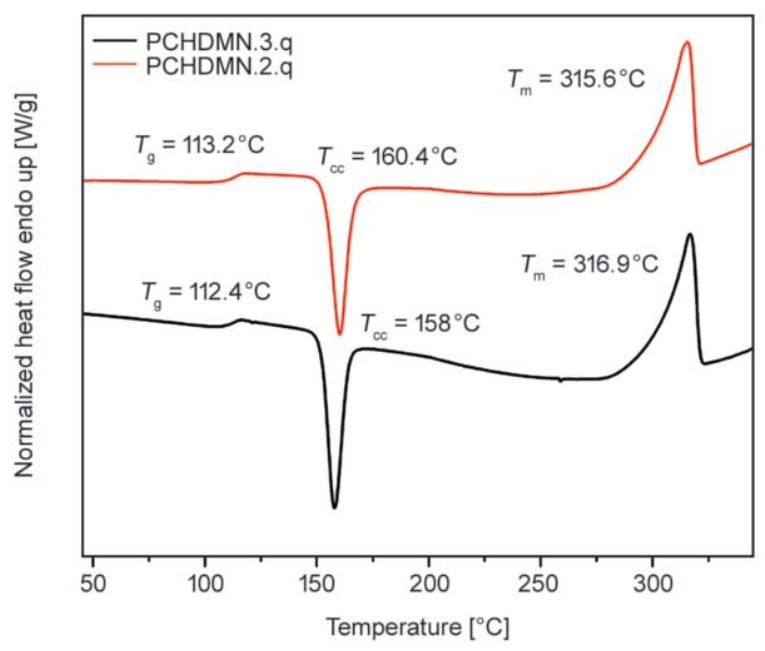

Figure 7. DSC traces of melt-quenched PCHDMN.2 and melt-quenched PCHDMN.3 samples 
Table 1. Identified pyrolysis products of the PCHDMN polyesters

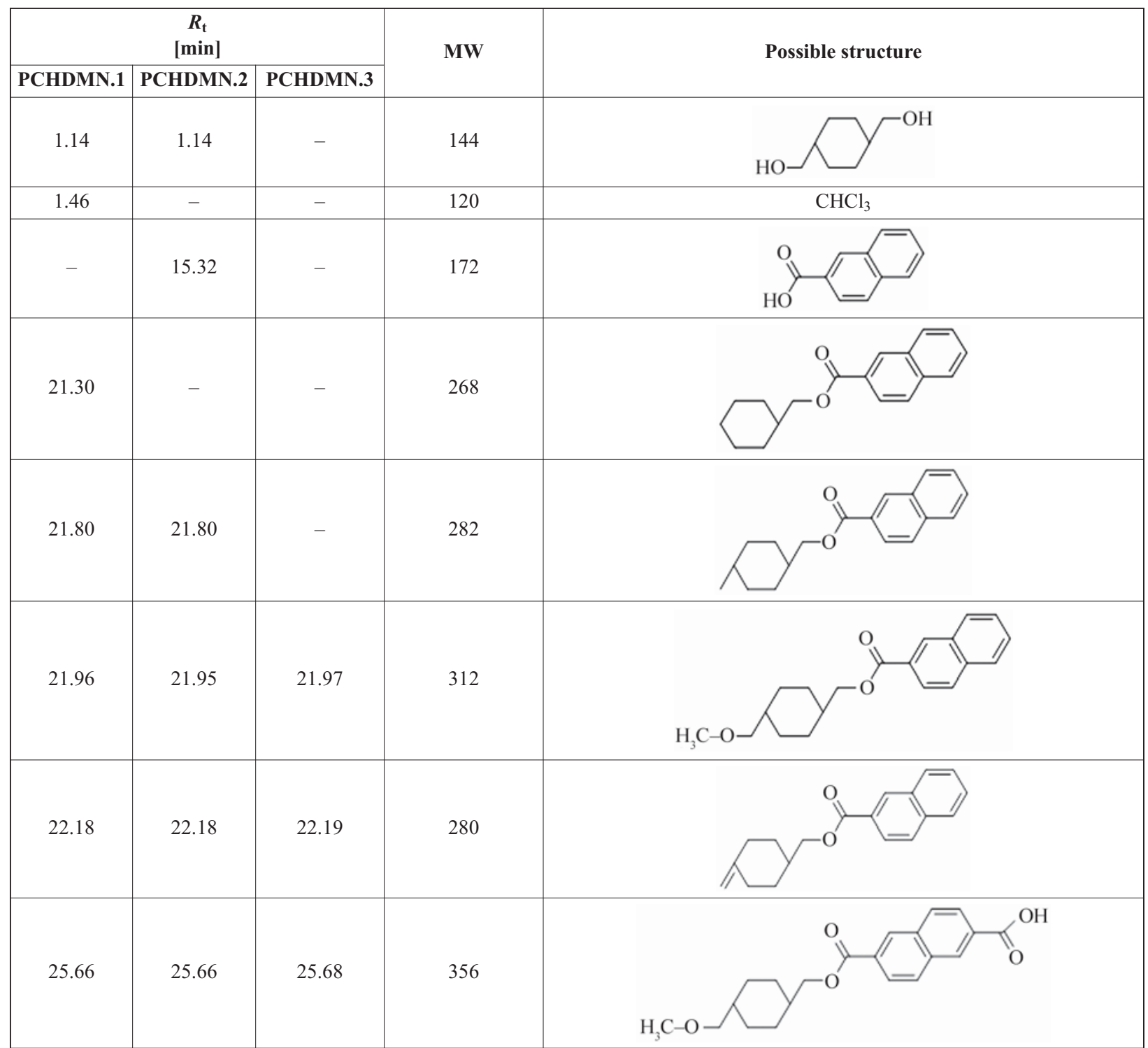

In order to further investigate the differences in the thermal stabilities of the three polyesters synthesized at different temperatures, Py-GC/MS measurements were performed. Pyrolysis took place at $350^{\circ} \mathrm{C}$, which corresponds to the initiation of degradation as concluded by TGA, and the resulting chromatographs are presented in Figure 8. Each peak is matched with a pyrolysis product, as identified by the corresponding MS spectra, and are presented in Table 1. Those decomposition products give valuable information about the degradation mechanism of the polyesters. Since the first in-depth study on the degradation of PET [17], it is generally agreed upon that polyesters with beta-hydrogens on their structure follow mainly the $\beta$-heterolytic scission pathway during thermal degradation, along with radical and $\alpha$-scission reaction in a smaller extent and only at higher temperatures [18-28]. In this study, Py/GC-MS was employed

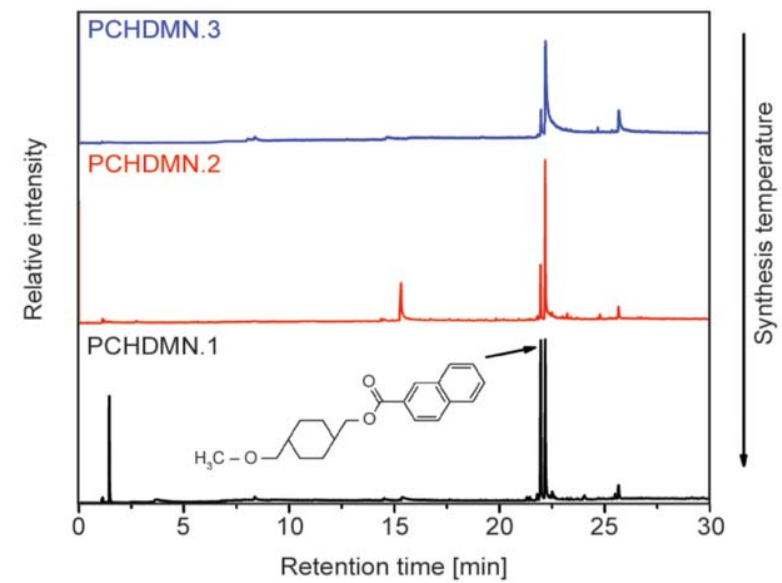

Figure 8. Chromatographs of the polyesters after pyrolysis at $350^{\circ} \mathrm{C}$

as a tool to investigate the reasons behind the differences on the thermal stability of the PCHDMN polyesters. 


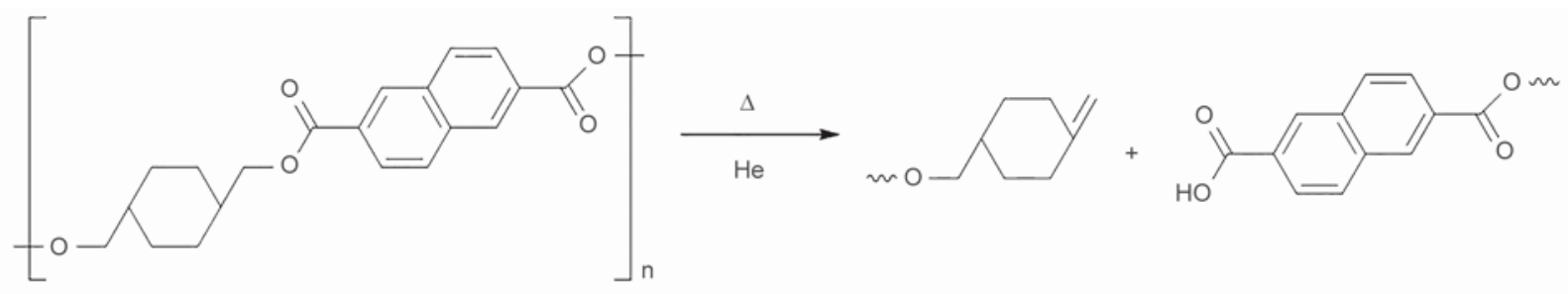

Figure 9. Heterolytic scission degradation pathway of PCHDMN

The three chromatographs of Figure 8 exhibit only a few peaks, with 2 of them being the most prominent for all the samples, at $R_{\mathrm{t}} \approx 22 \min$ and $R_{\mathrm{t}} \approx$ $22.2 \mathrm{~min}$. The first one was identified as (4(methoxymethyl)cyclohexyl)methyl 2-naphthoate, a methyl ester that can be derived during the transesterification stage of the synthesis procedure. This compound represents unreacted oligomer remnants that weren't sublimated, or degradation products of the macromolecular chain. It is noteworthy that the peak area of the particular compound is reducing as the reaction temperature is decreased (3 times smaller for PCHDMN.3 compared with PCHDMN.1), witnessing the superior thermal stability of PCHDMN.3, the polyester that was synthesized at the lower temperature. The second peak at $R_{\mathrm{t}} \approx 22.2$ min was identified as (4-methylenecyclohexyl) methyl 2-naphthoate, a vinyl-ended compound that is a decomposition product of the polyester. Vinylterminated compounds are the basic molecules that are released from $\beta$-scission of polyester macromolecular chains, and are thought to be responsible for yellow discoloration [26]. Similarly, this compound's peak area decreases while decreasing reaction temperature, indicating the superiority of the final polyester synthesized at $290^{\circ} \mathrm{C}$. These results are in agreement with TGA, viscosity and FTIR measurements.
Other minor compounds were also detected in the chromatographs, including the used diol, decarboxylated diacid, and carboxyl- terminated compounds. The main degradation pathway of PCHDMN is presented in Figure 9.

The polyester samples were also studied by using XRD. The recorded patterns (Figure 10) evidenced that PCHDMN.2, PCHDMN.3 polyesters are semicrystalline materials with well-defined sets of crystalline diffraction peaks at $2 \theta=8.5,11.05,15.7$, $17.53,18.41,20.73,23.4$, and 26.4 degrees, in accordance to reports in literature [9]. PCHDMN.1 samples are also semi-crystalline materials but with higher amorphous fraction, compared with the other studied polyesters. Also, the PCHDMN.1 patterns proved that the use of different polycondensation times has no effect on its crystalline structure, even though these polyesters have different molecular weights. All these findings are in good agreement with the DSC data.

Figure 11, shows indicative PLM photographs for PCHDMN.3 sample crystallized at different temperatures. The nucleation density decreased while the spherulite size increased with increasing temperature and time. PCHDMN showed large nucleation density and only at very low supercoolings this was reduced. In general, similar behaviors were observed for the
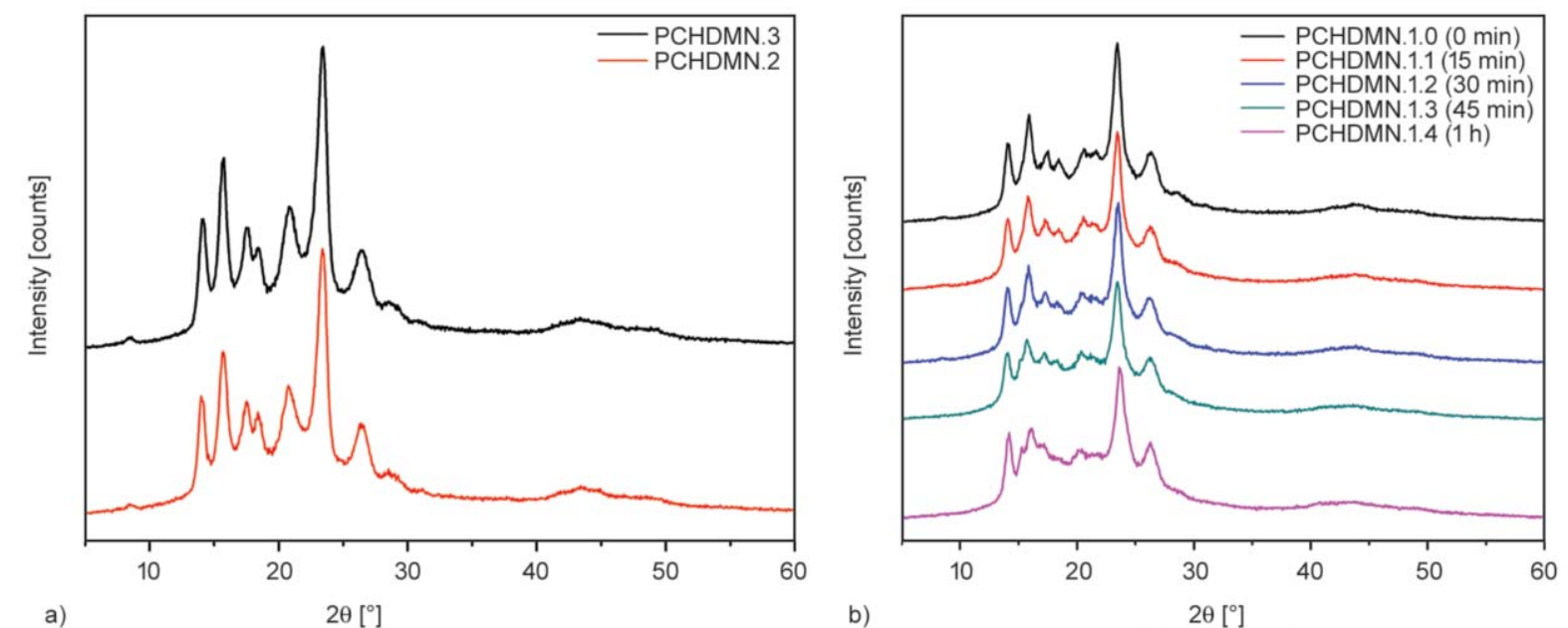

Figure 10. WAXD patterns of the as received samples during reaction time: a) PCHDMN.3 and PCHDMN.2 b) PCHDMN.1 


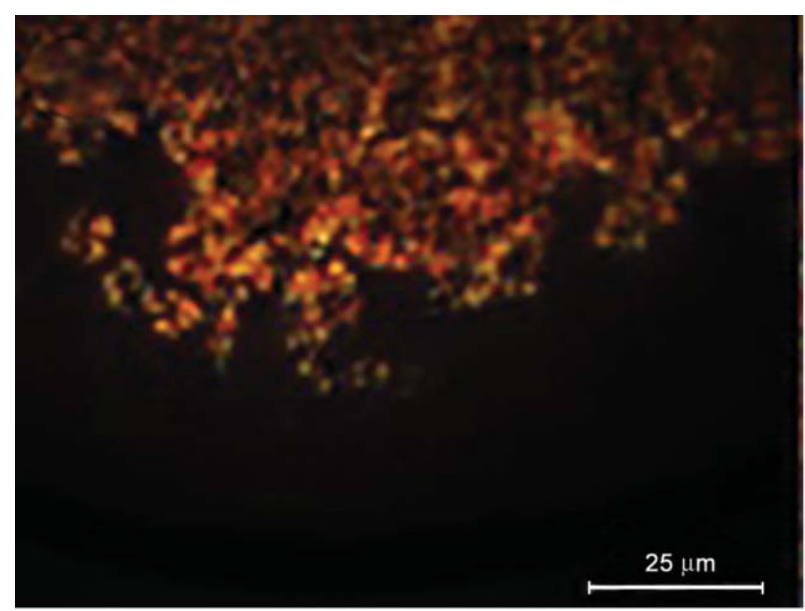

a)

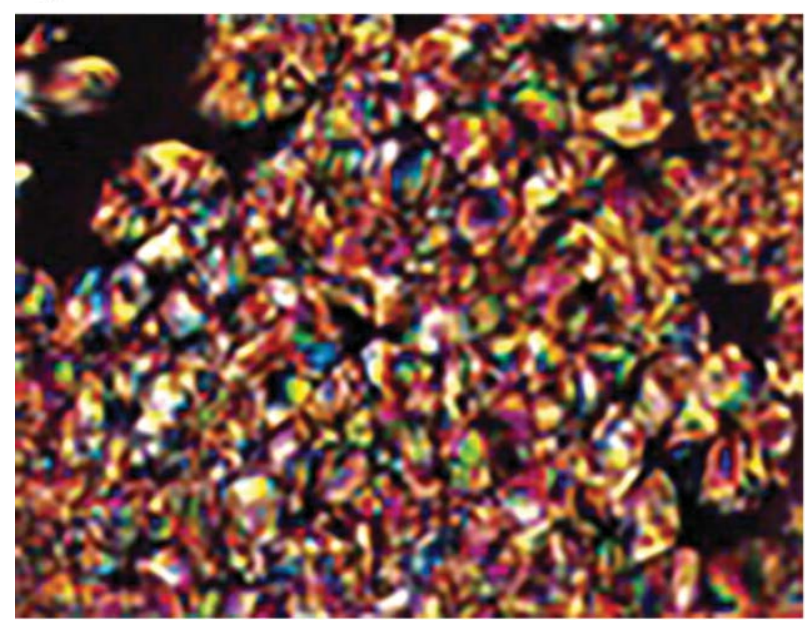

c)

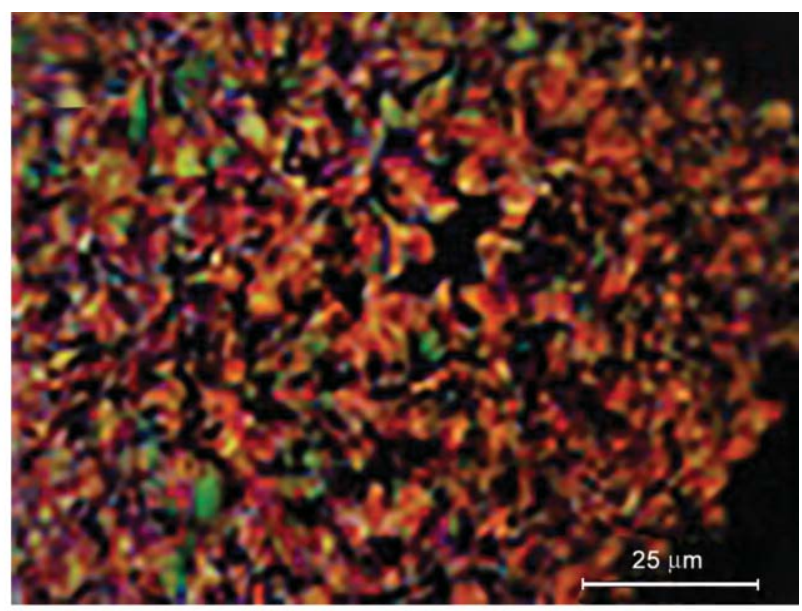

b)

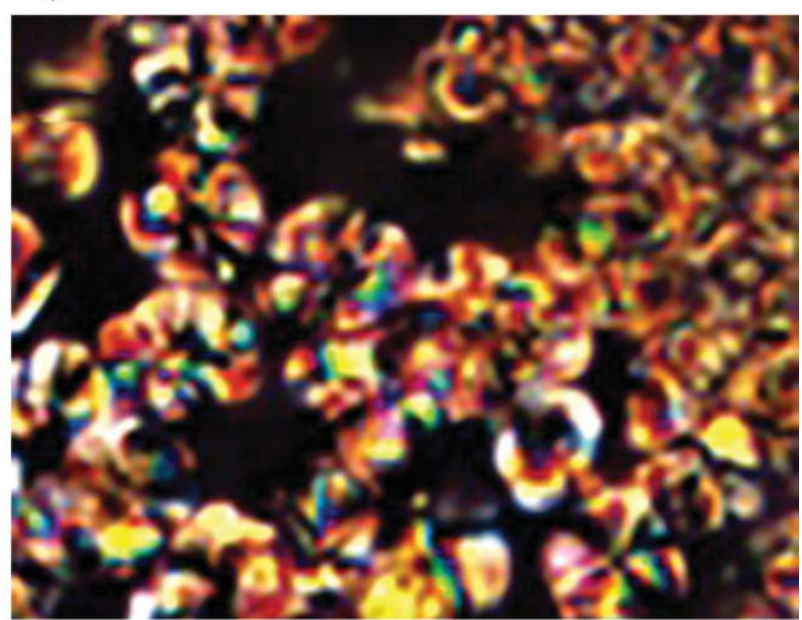

d)

Figure 11. PLM images showing spherulites of PCHDMN.3 grown at: a) $270^{\circ} \mathrm{C}$, b) $295^{\circ} \mathrm{C}$, c) $300^{\circ} \mathrm{C}$, d) $305^{\circ} \mathrm{C}$. Same magnification in all photos. The scale bar is $25 \mu \mathrm{m}$.

rest samples. Large nucleation density was also observed for PBN or PEN and at some extent for poly(trimethylene naphthalate) (PTN) [29-31], so this seems to be common characteristic of naphthalate polyesters.

\section{Conclusions}

In summary, we proved the efficiency of at least one new method as an effective, fast and simple synthesis pathway for preparation of poly $(1,4-$ cyclohexanedimethylene 2,6-naphthalate) via melt polycondensation process. It has been revealed, in this study, that a reaction temperature of $290^{\circ} \mathrm{C}$ and a short reaction time of $0.5 \mathrm{~h}$ are fully enough to produce PCHDMN having high molecular weight (IV value around $0.5 \mathrm{dL} / \mathrm{g}$ ). Higher polycondensation temperatures such as $340^{\circ} \mathrm{C}$, lead to formation of polyesters with lower molecular weights, due to thermal degradation.

\section{References}

[1] Meehan S. J., Sankey S. W., Jones S. M., MacDonald W. A., Colquhoun H. M.: Cocrystalline copolyimides of poly(ethylene 2,6-naphthalate). ACS Macro Letters, 3, 968-971 (2014).

https://doi.org/10.1021/mz500357z

[2] Cavallo D., Mileva D., Portale G., Zhang L., Balzano L., Alfonso G. C., Androsch R.: Mesophase-mediated crystallization of poly(butylene-2,6-naphthalate): An example of Ostwald's rule of stages. ACS Macro Letters, 1, 1051-1055 (2012).

https://doi.org/10.1021/mz300349z

[3] Neděla O., Slepička P., Kolská Z., Slepičková Kasálková N., Sajdl P., Veselý M., Švorčík V.: Functionalized polyethylene naphthalate for cytocompatibility improvement. Reactive and Functional Polymers, 100, 44-52 (2016). https://doi.org/10.1016/j.reactfunctpolym.2016.01.004

[4] Jeong Y. G., Jo W. H., Lee S. C.: Crystal structure of poly(hexamethylene 2,6-naphthalate). Polymer Journal, 33, 913-919 (2001).

https://doi.org/10.1295/polymj.33.913 
[5] Lorenzetti C., Finelli L., Lotti N., Vannini M., Gazzano M., Berti C., Munari A.: Synthesis and characterization of poly(propylene terephthalate/2,6-naphthalate) random copolyesters. Polymer, 46, 4041-4051 (2005). https://doi.org/10.1016/j.polymer.2005.03.054

[6] Liang Y., Lee H. S.: Conformational identification and phase transition behavior of poly(trimethylene 2,6naphthalate) $\alpha$-form modification. Macromolecules, 48, 5697-5705 (2015).

https://doi.org/10.1021/acs.macromol.5b01087

[7] Jeong Y. G., Jo W. H., Lee S. C.: Crystal structure of poly(pentamethylene 2,6-naphthalate). Polymer, 43, 7315-7323 (2002).

https://doi.org/10.1016/S0032-3861(02)00661-4

[8] Wang J., Liu X., Zhang Y., Liu F., Zhu J.: Modification of poly(ethylene 2,5-furandicarboxylate) with 1,4-cyclohexanedimethylene: Influence of composition on mechanical and barrier properties. Polymer, 103, 1-8 (2016). https://doi.org/10.1016/j.polymer.2016.09.030

[9] Jeong Y. G., Jo W. H.: Crystal structure determination of poly(1,4-trans-cylcohexylenedimethylene 2,6-naphthalate) by X-ray diffraction and molecular modeling. Macromolecules, 36, 5201-5207 (2003).

https://doi.org/10.1021/ma0215666

[10] Jeong Y. G., Jo W. H.: Synthesis and crystallization behavior of poly(m-methylene 2,6-naphthalate-co-1,4-cyclohexylenedimethylene 2,6-naphthalate) copolymers. Macromolecules, 36, 4051-4059 (2003). https://doi.org/10.1021/ma034094j

[11] Jeong Y. G., Jo W. H., Lee S. C.: Synthesis and isodimorphic cocrystallization behavior of poly $(1,4-c y c l o-$ hexylenedimethylene terephthalate-co-1,4-cyclohexylenedimethylene 2,6-naphthalate) copolymers. Journal of Polymer Science Part B: Polymer Physics, 42, 177-187 (2004).

https://doi.org/10.1002/polb.10691

[12] Tsai Y., Fan C-H., Hung C-Y., Tsai F-J.: Amorphous copolyesters based on 1,3/1,4-cyclohexanedimethanol: Synthesis, characterization and properties. Journal of Applied Polymer Science, 109, 2598-2604 (2008). https://doi.org/10.1002/app.28385

[13] Hoffman D. C., Pecorini T. J.: Copolyesters of poly (1, 4-cyclohexanedimethylene terephthalate) with isophhalic acid and 2,6-naphthalene dicarboxylic acid. in 'Amer National American Chemical Society Meeting, Anaheim, USA' 290/1-290/2 (1999).

[14] Tsanaktsis V., Papageorgiou G. Z., Bikiaris D. N.: A facile method to synthesize high-molecular-weight biobased polyesters from 2,5-furandicarboxylic acid and long-chain diols. Journal of Polymer Science Part A: Polymer Chemistry, 53, 2617-2632 (2015). https://doi.org/10.1002/pola.27730

[15] Hong S., Min K-D., Nam B-U., Park O. O.: High molecular weight bio furan-based co-polyesters for food packaging applications: synthesis, characterization and solid-state polymerization. Green Chemistry, 18, 51425150 (2016).

https://doi.org/10.1039/C6GC01060A
[16] Turner S. R., Seymour R. W., Dombroski J. R.: Amorphous and crystalline polyesters based on 1,4-cyclohexanedimethanol. in 'Modern polyesters: Chemistry and technology of polyesters and copolyesters' (eds.: Scheirs J. L., Long T. E.) Wiley, Chichester, 267-292 (2004).

https://doi.org/10.1002/0470090685.ch7

[17] Buxbaum L. H.: The degradation of poly(ethylene terephthalate). Angewandte Chemie International Edition, 7, 182-190 (1968).

https://doi.org/10.1002/anie.196801821

[18] Botelho G., Queirós A., Liberal S., Gijsman P.: Studies on thermal and thermo-oxidative degradation of poly(ethylene terephthalate) and poly(butylene terephthalate). Polymer Degradation and Stability, 74, 39-48 (2001).

https://doi.org/10.1016/S0141-3910(01)00088-X

[19] Samperi F., Puglisi C., Alicata R., Montaudo G.: Thermal degradation of poly(ethylene terephthalate) at the processing temperature. Polymer Degradation and Stability, 83, 3-10 (2004).

https://doi.org/10.1016/S0141-3910(03)00166-6

[20] Levchik S. V., Weil E. D.: A review on thermal decomposition and combustion of thermoplastic polyesters. Polymers for Advanced Technologies, 15, 691-700 (2004).

https://doi.org/10.1002/pat.526

[21] Tsanaktsis V., Vouvoudi E., Papageorgiou G. Z., Papageorgiou D. G., Chrissafis K., Bikiaris D. N.: Thermal degradation kinetics and decomposition mechanism of polyesters based on 2,5-furandicarboxylic acid and low molecular weight aliphatic diols. Journal of Analytical and Applied Pyrolysis, 112, 369-378 (2015).

https://doi.org/10.1016/j.jaap.2014.12.016

[22] Tsanaktsis V., Terzopoulou Z., Exarhopoulos S., Bikiaris D. N., Achilias D. S., Papageorgiou D. G., Papageorgiou G. Z.: Sustainable, eco-friendly polyesters synthesized from renewable resources: Preparation and thermal characteristics of poly(dimethyl-propylene furanoate). Polymer Chemistry, 6, 8284-8296 (2015). https://doi.org/10.1039/C5PY01367D

[23] Terzopoulou Z., Tsanaktsis V., Nerantzaki M., Achilias D. S., Vaimakis T., Papageorgiou G. Z., Bikiaris D. N.: Thermal degradation of biobased polyesters: Kinetics and decomposition mechanism of polyesters from 2,5furandicarboxylic acid and long-chain aliphatic diols. Journal of Analytical and Applied Pyrolysis, 117, 162175 (2016).

https://doi.org/10.1016/j.jaap.2015.11.016

[24] Terzopoulou Z., Tsanaktsis V., Nerantzaki M., Papageorgiou G. Z., Bikiaris D. N.: Decomposition mechanism of polyesters based on 2,5-furandicarboxylic acid and aliphatic diols with medium and long chain methylene groups. Polymer Degradation and Stability, 132, 127-136 (2016).

https://doi.org/10.1016/j.polymdegradstab.2016.03.006 
[25] Konstantopoulou M., Terzopoulou Z., Nerantzaki M., Tsagkalias J., Achilias D. S., Bikiaris D. N., Exarhopoulos S., Papageorgiou D. G., Papageorgiou G. Z.: Poly (ethylene furanoate-co-ethylene terephthalate) biobased copolymers: Synthesis, thermal properties and cocrystallization behavior. European Polymer Journal, 89, 349-366 (2017).

https://doi.org/10.1016/j.eurpolymj.2017.02.037

[26] Terzopoulou Z., Karakatsianopoulou E., Kasmi N., Majdoub M., Papageorgiou G. Z., Bikiaris D. N.: Effect of catalyst type on recyclability and decomposition mechanism of poly(ethylene furanoate) biobased polyester. Journal of Analytical and Applied Pyrolysis, 126, 357 370 (2017).

https://doi.org/10.1016/j.jaap.2017.05.010

[27] Terzopoulou Z., Kasmi N., Tsanaktsis V., Doulakas N., Bikiaris D. N., Achilias D. S., Papageorgiou G. Z.: Synthesis and characterization of bio-based polyesters: Poly(2-methyl-1,3-propylene-2,5-furanoate), poly(isosorbide-2,5-furanoate), poly(1,4-cyclohexanedimethylene2,5-furanoate). Materials, 10, 801-819 (2017).

https://doi.org/10.3390/ma10070801
[28] Terzopoulou Z., Patsiaoura D., Papageorgiou D. G., Pavlidou E., Chrissafis K., Tzounis L., Papageorgiou G. Z., Bikiaris D. N.: Effect of MWCNTs and their modification on crystallization and thermal degradation of poly(butylene naphthalate). Thermochimica Acta, 656, 59-69 (2017).

https://doi.org/10.1016/j.tca.2017.08.012

[29] Papageorgiou G. Z., Tsanaktsis V., Bikiaris D. N.: Crystallization of poly(butylene-2,6-naphthalate-co-butylene adipate) copolymers: Regulating crystal modification of the polymorphic parent homopolymers and biodegradation. CrystEngComm, 16, 7963-7978 (2014). https://doi.org/10.1039/C4CE00651H

[30] Papageorgiou G. Z., Achilias D. S., Karayannidis G. P.: Estimation of thermal transitions in poly(ethylene naphthalate): Experiments and modeling using isoconversional methods. Polymer, 51, 2565-2575 (2010). https://doi.org/10.1016/j.polymer.2010.04.031

[31] Papageorgiou G. Z., Papageorgiou D. G., Tsanaktsis V., Bikiaris D. N.: Synthesis of the bio-based polyester poly(propylene 2,5-furan dicarboxylate). Comparison of thermal behavior and solid state structure with its terephthalate and naphthalate homologues. Polymer, 62, 28-38 (2015).

https://doi.org/10.1016/j.polymer.2015.01.080 